\title{
A Study of Cultural Context in Chinese-English Translation
}

\author{
Xiang'e Zhang \\ Chongqing Information Technology College, Chongqing, China
}

\begin{abstract}
The cultural translation view considers translation as a cross-cultural communication activity. The paradigm and thinking of translation will also have profound changes in different cultural contexts. It can be seen from modern translation studies that the translation circle has paid full attention to the cultural differences between the two languages, and due to the profound influence of culture, translators have gradually formed their own unique and personalized cultural understanding and translation concepts in translation practice. Starting from the influence of cultural context on ChineseEnglish translation, this article explores the cultural context in Chinese-English translation combined with practical work experience, and the understanding and practice of translation activities under the cultural translation perspective.
\end{abstract}

Key words: Chinese-English translation; cultural context

\section{Introduction}

Translation is an interactive process of cognitive experience among authors, translators and readers. From the perspective of traditional translation theory, the core of translation lies in text conversion, that is, to use the target language to fully and accurately express the style and thoughts presented in the source language. With the deepening of translation theory and research, most scholars questioned the traditional translation view and formed a new translation theory, thus the cultural translation view came into being. It points out that culture is equal without difference between strength and weakness. It advocates highlighting the unique charm of different cultures in translation practice, so that readers with different cultural backgrounds can communicate at the cultural significance level through translation. In the ChineseEnglish translation, Chinese words such as "kowtow" and "kungfu" have entered English dictionaries, which shows that cultural exchanges are interactive and the influence of Chinese and Western cultures is also bidirectional.Therefore, only by recognizing the differences between Chinese and English languages and adhering to cultural self-confidence when translating can we weaken the influence of cultural differences between China and the West on translation, and then ensure that the translation is compatible with cultural context.The following will start from the perspective of Chinese-English translation to explain the cultural context in Chinese-English translation based on actual translation cases.

\section{The Influence of Cultural Context on Chinese-English Translation}

2.1 The influence of cultural vacancy on Chinese-English translation

From the perspective of cultural translation, translation is not only a process of language transcoding, but also a process of presenting the connotation of source language culture to target readers. The Chinese and Western cultures are quite different, so there will be a phenomenon that the Chinese culture is unique.

Copyright (C) 2021 by author(s) and Frontier Scientific Research Publishing Inc.

This work is licensed under the Creative Commons Attribution International License (CC BY 4.0).

http://creativecommons.org/licenses/by/4.0/ 
First, words that condense Confucian and Taoist ideas and reflect China's unique concept of life and cultural spirit will fail to express their cultural connotations when translated due to cultural vacancies. For example, the translation of “缘 分" into "lucky" lacks the dialectical unity of inevitability and contingency. And some words are difficult to be suitable and appropriate in the English language system, such as the Chinese Heavenly Stems, Earthly Branches, Eight Diagrams, lunar solar terms, traditional Chinese medicine terms, etc.

Second, not only the traditional Chinese culture, but also the economic development and political systems of China and the West are obviously different. Contemporary Chinese-English translation will also encounter greater difficulties due to cultural differences. For example, the literal translation of “加油” as "add oil” obviously does not conform to the semantics of the original word, and if it is translated as "Good luck", it lacks the meaning of "effort". Another example is the word “小吃”, which does not exist in Western culture. In the food category, “小吃” belongs to neither “snacks” nor “appetizers”. Therefore, it is difficult to express the cultural connotation of “小吃” in a single word.

Third, the difference between Chinese and Western language thinking and culture is mainly manifested in the translation of "Chinese thinking". Chinese language is euphemistic and implicit, while Western language thinking presents a straight line. Therefore, Chinese sentence structure is loose and fluent in writing, logically restrained, and emphasizes the contrast and neatness, while Western sentences are mainly "hypotaxis", focusing on the echo of tenses and obvious forms of connection.

\subsection{The impact of semantic ambiguity conflict on Chinese-English translation}

Culture is a necessary condition for the production of language, and language is the carrier of culture. The differences between Chinese and Western cultures will inevitably lead to ambiguities and even conflicts in the cultural information carried in the language. British linguist Firth pointed out that the same word has different meanings in different language environments. And this polysemy leads to the lack of one-to-one correspondence between Chinese and English vocabulary, which is also one of the main reasons why the meaning of words is difficult to determine in Chinese-English translation. The cultural vacancy mentioned above is actually a phenomenon of vocabulary vacancy in English-Chinese translation. In addition, there are semantic conflicts and inconsistencies in semantic associations, which are triggered by cultural differences, and have a profound impact on translation practice.

The first is semantic conflict. For example, “干部” in Chinese is often translated as "cadre", meaning a part of the elite in a unit in the Cambridge Dictionary, which obviously do not match the semantics. Moreover, "cadre" is an uncommon vocabulary for native English speakers, so such a translation cannot achieve cultural communication. Therefore, some scholars suggest that “干部” should be translated into "official” or "administrator", but these English words are not semantically equivalent to it.

Second, the semantic associations are inconsistent. Zhu Guangqian pointed out that semantic associations have subtle but deep emotions. If you are not familiar with a country's customs and cultural and historical background, the meaning of the translation will be vague. The differences between Chinese and Western customs and cultural and historical backgrounds put forward higher requirements for translators to control semantic associations. For example, in our country, "east wind" brings spring, which means warmth, luck and beauty. But in Britain, as it is located in the southern hemisphere, "east wind" often means cold and winter is approaching. Therefore, in the translation practice, we must pay attention to the cultural information carried in the source language, and avoid the ambiguity of readers due to semantic conflicts and inconsistent semantic connections. 


\section{A Study of Cultural Context in Chinese-English Translation}

3.1 Be loyal to the original text and strengthen the semantic association of the text

The differences between Chinese and Western customs and cultural and historical backgrounds lead to the inconsistenty in semantic associations of Chinese and Western languages, and the cultural information contained in them is also different, which requires translators to adopt foreignization or domestication flexibly in order to achieve the translation goal. The foreignization means that the translation takes the source language culture as the basic principle, and the domestication refers to the target language culture as the destination of the translation. Translation not only has the function of cultural exchange, but also is the carrier of cultural communication. If cultural exchange is the main purpose, it is recommended to adopt the domestication. For example, in the alienation translation of “骄傲使人进步, 谦虚使人落 后”, the source language is Chinese slang, and “juxtaposition and transition” is implicit between the two sentences, but Chinese language pursues neat structure and smooth writing, so the conjunctions like "and or but" are omitted. When the foreignization is used for translation, the "whereas" connective can connect two sentences to achieve "hypotaxis", so that the target language readers can better understand the meaning of Chinese slang. For text translation with the goal of cultural dissemination, foreignization can be adopted. Take the "Book of Songs·Jianjia" translated by Xu Yuanchong as an example. He translated “苍苍” and “妻妻” into “The reeds grow green”, “The reeds turns white” and “The reeds still there", reflecting the seasonal changes. The passage of time reflects the hardship and length of the poet's painstaking pursuit, and the expression of "combining emotion with scenery, and mixing up feeling and sight" in Chinese classical literature works, with strong Chinese cultural connotations.

3.2 Eliminate vacancies by adopting transliteration and substitution methods

The vacancy phenomenon of Chinese and Western cultures has led to the fact that Chinese and English vocabulary are not "one-to-one". Some words that reflect Confucianism, Taoism, traditional Chinese customs, and unique architectural styles are difficult to find corresponding words in the English language system. Therefore, it is necessary to use transliteration and substitution appropriately when translating. In Chinese-English translation, the transliteration refers to the translation of specific words by means of Chinese pinyin marking, which is suitable for complete vacancies in the meaning of words. For example, the general transliteration of “阴” and “阳” in Chinese Eight Diagrams is “Yin” and "Yang”, and the “气功” in Chinese medicine theory is transliterated as "qigong”. While substitution refers to replacing the words of the source language with more appropriate English vocabulary without changing the meaning, which is suitable for the translation of words in the form of idioms. For example, “精神文明” is a major national strategy in our country. It not only means the construction of ideological and spiritual levels, but also involves moral and legal norms. If it is literally translated as "spiritual civilization", it is difficult to reflect the multi-level cultural connotation of "spiritual civilization" and the spiritual outlook of the Chinese sons and daughters in action to promote the construction of spiritual civilization, so it can be translated as “cultural and ethical progress”. Another example is the translation of “挥金如土” as “spend money like water" instead of "spend money like soil". It replaces “土” with "water", which fully takes into account the differences in the concept of money between China and the West.

3.3 Do a little bit of processing to resolve language and cultural conflicts

In the translation of Chinese traditional cultural texts, there are many proper nouns with standard translation methods. The unity of translation can ensure the consistency of the spread of Chinese cultural connotation to the greatest extent, and can also make the target readers understand Chinese culture more intuitively. For example, “元宵节” is translated as “Yuanxiao Festival”, “端午节” is translated as “Duanwu Festival” and so on. While literal translation is not applicable to 
other sentences in the text. The translator needs to understand the cultural connotation behind the language and dig out the deep cultural information of the language. On the one hand, it can ensure the transmission of cultural connotation, and on the other hand, it is easy for readers of the target language to understand. For example, when translating “长城经历了两千 余年的沧桑”, “沧桑” in this sentence means changes in time or years, which can be translated as "The Great Wall had a history more than 2000 years". In this way, a slight treatment of the differences between English and Chinese languages can allow target language readers to understand the long history of the Great Wall of China.

\subsection{Learn culture to actively broaden cultural horizons}

In Chinese-English translation, whether it is for cultural exchange or cultural communication, it is necessary for translators to have a deep understanding of Chinese and Western cultures in order to truly feel the semantics of languages and the cultural information contained in different cultural contexts. At the same time, with the development of society and the further deepening of the integration of Chinese and Western cultures, profound changes have taken place in all aspects of history, geography, politics, and technology in Chinese and Western countries, which not only enriched the vocabulary, but also extends the breadth and depth of the meaning. Therefore, only by keeping pace with the times and strengthening accumulation can we meet the needs of Chinese-English translation. For example, China's economic development has been advancing by leaps and bounds in recent years. Especially the network economy is developed, the network has become the main position for people to socialize and express their views. Internet hot words are emerging in an endless stream, and an open "internet language culture" has gradually formed. Therefore, paying attention to the accumulation of network language and trying to translate it into English can improve the translation practice ability. Another example is that the new western vocabulary is also increasing, and the language and culture has also undergone certain changes. Understanding Western culture and its connotation can ensure that the translation conforms to the language expression habits and life customs of Western readers.

\section{Conclusions}

Culture is the source of language, and language is the carrier of culture. The two have a strong internal connection and logical relationship. The difference of cultural context will have a profound impact on Chinese and English translation, which is manifested in cultural vacancy and conflict of semantic ambiguity. In order to minimize the negative impact of cultural differences on translation, it is necessary to deepen the understanding of Chinese and Western cultures, explore ways to promote cultural exchange and Chinese cultural transmission based on the perspective of cultural translation, and adopt scientific, reasonable and appropriate translation methods to shape the translation into the carrier of cultural exchange and communication.

\section{Conflicts of Interest}

The author declares no conflicts of interest regarding the publication of this paper.

\section{References}

[1] Han Y.F. (2021). Research on the Performance of Untranslatability in Different Systems of Chinese and English Cultures. Journal of Hubei Open Vocational College, 34(01): 184-185.

[2] Wang Z.H. (2021). Translator as a Cultural Phenomenon: An Entry Point for Translator Research. Yangtze River Academic, (01): 87-96.

[3] Li X.Y. (2020). An Analysis of the Influence of Chinese and Western Cultural Differences on English Translation. Overseas English, (24): 231-232.

[4] Wang Q. and Liu B. (2020). Cross-cultural Translation Research Based on Domestication and Foreignization Strategies---Taking the English Version of "To Live" as an Example. Journal of West Anhui University, 36(06): 112-118. 